\title{
Assessment of Story Comprehension Deficits After Brain Damage
}

\author{
EVELYN C. FERSTL, ${ }^{1,2}$ KATRIN WALTHER, ${ }^{1}$ \\ THOMAS GUTHKE ${ }^{1}$ AND D. YVES VON CRAMON ${ }^{1,2}$ \\ ${ }^{1}$ Day Clinic for Cognitive Neurology, University of Leipzig, Leipzig, Germany \\ ${ }^{2}$ Max-Planck-Institute of Human Cognitive and Brain Sciences, Leipzig, Germany
}

\begin{abstract}
A story comprehension task was specifically developed for the clinical diagnosis of text comprehension deficits. The performance of 49 healthy control participants on qualitatively different Yes/No questions confirmed that both salience and explicitness of information had an impact on question difficulty. An unselected group of brain damaged patients $(n=96)$ made more errors, particularly on questions about implicit information. The subgroup of patients with left-hemispheric vascular aetiology $(n=18)$ had particular difficulties with stated details, patients with right-hemispheric vascular aetio$\operatorname{logy}(n=12)$ with implicit main ideas, and patients with traumatic brain injury $(n=34)$ were most impaired on implicit information. Correlations with neuropsychological test scores also confirmed that the questions successfully tapped different subprocesses of comprehension. Performance on implicit main ideas was correlated with tests of executive functions, whereas the performance on the other three question types was correlated with long-term memory and verbal learning. These results suggest that the story comprehension test is a useful diagnostic tool for neuropsychological assessment.
\end{abstract}

\section{Introduction}

Sufficient communication skills, and in particular, language comprehension abilities are a prerequesite for a positive rehabilitative outcome after brain damage (Brooks, McKinlay, Symington, Beattie \& Campsie, 1987). Therefore, an estimation of a patient's prognosis requires an ecologically valid assessment of the comprehension of language in context. However, this complex skill depends on a large variety of cognitive processes. Besides the decoding of the message using linguistic processes, comprehension requires sufficient attention when longer texts are to be understood, verbal working memory for keeping successive utterances in mind, verbal learning for transferring the text content into a longterm memory representation, and finally the use of executive functions, such as structuring of the information or monitoring the comprehension success. Deficits in any of these cognitive processes might prohibit patients from fully understanding language in context.

More specifically, neurolinguistic research distinguishes two types of communication deficits. Aphasic language disturbances denote impairments, in either comprehension or production, on the phonological, lexical, semantic or syntactic levels of language use (Caplan, 1992). In contrast, non-aphasic language deficits are situated on the contextual and pragmatic levels of communication in context (e.g., Kaczmarek, 1984, 1987; McDonald, 1993; Novoa \& Ardila, 1987; Prigatano, Roueche \& Fordyce, 1986).

Address correspondence to: Evelyn C. Ferstl, Max-Planck-Institute of Human Cognitive and Brain Sciences, Stephanstr. 1 A, 04103 Leipzig, Germany. E-mail: ferstl@cbs.mpg.de

Received 31 March 2004; accepted 3 May 2004. 
An assessment of the comprehension skills is needed for both aphasic and non-aphasic patients. Patients with mild or moderate aphasia, usually after left hemispheric brain damage (LBD), have been shown to perform better when a facilitative context is presented (Germani \& Pierce, 1992; Guthke, Hauptmann, \& Ferstl, 2001; Pierce, 1988) and their comprehension skills on the text level are not necessarily correlated with aphasia test scores (e.g., Caplan \& Evans, 1990). Thus, text comprehension assessment can supplement aphasia testing by providing information about how the aphasic patient might benefit from context during the comprehension process. In contrast, non-aphasic communication deficits affect patients after traumatic brain injury (TBI; Chapman, Levin \& Culhane, 1995; Hartley \& Levin, 1990) and/or right hemisphere damage (RBD; Brownell \& Martino, 1998; McDonald, 1993). Most often apparent in inappropriate language production, these deficits can also affect text and discourse comprehension beyond the sentence level.

Distinct from language processing on the word and sentence levels, psycholinguistic theories postulate two crucial components of text comprehension (Kintsch, 1998). The first component process, inferencing, refers to an augmentation of the explicitly stated information by additional contents taken from general world knowledge (Graesser, Singer \& Trabasso, 1994; Singer, 1994). Neurolinguistic studies have provided evidence for inferencing deficits in patients with right hemisphere brain damage and in patients with frontal lobe lesions (Brownell \& Martino, 1998; Ferstl, Guthke \& von Cramon, 2002; see also Beeman, 1993; Lehman \& Tompkins, 2000; McDonald \& Wales, 1986). The second process is the extraction of the so-called macrostructure, that is, of a global structure of the text comparable to a summary or an outline of the text (Kintsch, 1998; Kintsch \& van Dijk, 1978; van Dijk \& Kintsch, 1983). Once more, in contrast to aphasic patients, who observe macrostructure rules during production (Ulatowska \& Chapman, 1994), right hemisphere patients have been shown to have difficulties with setting up a macrostructure (e.g., Hough, 1990; Webster, Godlewski, Hanley \& Sowa, 1992). Some of the discourse production problems observed in non-aphasic language deficits can be attributed to the failure to use an appropriate macrostructure during production. A specific subprocess needed for building the macrostructure is the evaluation of the salience of information, that is, the ability to distinguish main ideas from details.

Brookshire and Nicholas (1993) developed a discourse comprehension test (DCT) for targeting these two different text comprehension processes. Using a yes/no-question format, this test crosses the factors explicitness (stated/implicit) and salience (main idea/ detail). In a number of studies (Brookshire \& Nicholas, 1984; Nicholas \& Brookshire, 1986, 1995; Wegner, Brookshire \& Nicholas, 1984) they confirmed that performance on explicitly mentioned information is better than on implicit information-indicating the relative difficulty of inference processes - and that main ideas are more reliably understood than details-indicating that a macrostructure is derived. Moreover, the two factors interacted, with a larger effect of explicitness on details than on main ideas.

However, despite the predictions of RBD patients and TBI patients having particular problems with inferencing and/or the evaluation of salience, Nicholas and Brookshire (1995) reported quantitative, but no qualitative differences in text comprehension skills for patients with LBD, RBD and TBI, respectively. All patient groups evidenced sensitivity to the factors salience and explicitness (cf. Haut, Petros \& Frank, 1990, for a comparable finding for TBI patients). Similarly, Welland, Lubinski, \& Higginbotham (2002) reported quantitative but no qualitative differences between Alzheimer patients and a healthy comparison group. In contrast, Murray and Stout (1999) reported lower overall performance levels in patients with Parkinson's or with Huntington's disease, and an additional qualitative difference between these two groups. 
One possibility for the DCT's failure to distinguish LBD, RBD and TBI performance is that the DCT stories, consisting of only a small number of sentences (about 200 words), were not sufficiently demanding for uncovering more subtle deficits, in particular with respect to the macrostructure. In the present study we report data on a German story comprehension task (SCT) developed specifically for the diagnosis of text comprehension deficits after brain damage. It is based on the same principle as the DCT, varying the factors explicitness and salience using simple yes/no-questions. The main difference is that the comprehension task uses two stories only, both of which are considerably longer than each of the ten DCT stories. This manipulation was intended to increase the demands on macrostructure processing. The second difference was that the questions on implicit details were constructed in a slightly different way. In the DCT, details are defined as referring to one content unit only. In contrast, many of the implicit detail questions used in the SCT could be answered by integrating several information sources which were not macrostructure relevant. Although this construction principle was expected to render the implicit detail questions easier for comparison participants, we hypothesized that the questions would be more sensitive to inference deficits.

The goal was first to provide comparison data from a group of non-brain damaged participants, confirming the differential effects of explicitness and salience on question difficulty. Second, we wanted to test whether the SCT would yield systematic, qualitative differences for patients depending on lesion lateralization and/or aetiology. For this group analysis we followed the approach of Nicholas and Brookshire (1995) and included groups with unilateral left-sided or right-sided lesions (LBD, RBD) and a group with traumatic brain injury (TBI). For the TBI patients - all of whom evidenced traumatic tissue damage-we used no specific information regarding lesion lateralization, but it is well known that TBI often causes frontal dysfunction (Levin et al., 1987). The predictions were that the two groups prone to non-aphasic language deficits (RBD, TBI) would evidence more difficulties with implicit information or main ideas, whereas the patients more prone to aphasic language deficits (LBD) would have specific problems with questions about stated and detail information. And thirdly, a critical analysis of the instrument's utility for clinical diagnosis was attempted. To this end, we evaluated coocurrence with other cognitive deficits, particularly in the domains of executive functions and of verbal memory and verbal learning.

\section{Method}

\section{Subjects}

For the comparison group 50 adults with no known history of neurological disorders (NBD-subjects) were recruited. The patient group consisted of 109 successively admitted patients with brain damage (BD), treated at the Day Clinic for Cognitive Neurology at the University of Leipzig. All participants were native speakers of German. The groups were matched with respect to age $\left(\mathrm{t}(143)<1\right.$; n.s.) and education $\left(\chi^{2}(2)=2.3\right.$; n.s.), but there were more men in the BD group than in the NBD group $\left(\chi^{2}(1)=4.9 ; \mathrm{p}<.05\right)$. The BD participants had suffered brain injuries of various aetiologies. The median time since lesion was 11 months (range 2-360 months). All patients received neuropsychological and/or speech therapy. Patients with dementia or global aphasia, severe hearing deficits, or any other deficits clearly preventing them from performing the task were excluded from participation.

For testing the influence of lesion lateralization and aetiology we used the classification from Nicholas and Brookshire (1995). Three subgroups were formed: patients with 
Table 1

Demographic Information for the Participants

\begin{tabular}{|c|c|c|c|c|c|c|c|}
\hline & \multicolumn{2}{|c|}{ Gender } & \multirow{2}{*}{$\frac{\text { Age (years) }}{\text { Mean (Range) }}$} & \multicolumn{3}{|c|}{$\begin{array}{l}\text { Schooling (no. } \\
\text { of participants) }\end{array}$} & \multirow{2}{*}{$\begin{array}{c}\begin{array}{c}\text { Months post } \\
\text { injury }\end{array} \\
\text { Median (Range) }\end{array}$} \\
\hline & $\mathrm{N}$ & $(\mathrm{M} / \mathrm{F})$ & & 8 yrs. & 10 yrs. & 13 yrs. & \\
\hline NBD control & 49 & $25 / 24$ & $44(20-69)$ & 9 & 23 & 17 & \\
\hline BD patients & 96 & $67 / 29$ & $42(15-71)$ & 16 & 57 & 23 & $11(2-360)$ \\
\hline TBI & 34 & $27 / 7$ & $34(17-57)$ & 2 & 25 & 7 & $13(3-229)$ \\
\hline LBD & 18 & $11 / 7$ & $51(27-71)$ & 4 & 12 & 2 & $7(2-72)$ \\
\hline RBD & 12 & $8 / 4$ & $51(33-69)$ & 4 & 6 & 2 & $10(3-194)$ \\
\hline
\end{tabular}

Note. $\mathrm{NBD}=$ not brain damaged, $\mathrm{BD}=$ brain damaged, $\mathrm{TBI}=$ traumatic brain injury, $\mathrm{LBD}=$ leftsided brain damage, $\mathrm{RBD}=$ right-sided brain damage, $\mathrm{M}=$ male, $\mathrm{F}=$ female.

a cerebrovascular infarction in the left $(\mathrm{LBD} ; \mathrm{n}=18)$ or right hemisphere $(\mathrm{RBD} ; \mathrm{n}=14)$ and patients with traumatic brain injury $(\mathrm{TBI} ; \mathrm{n}=38)$. Thirty-nine patients could not be assigned to one of these three groups. Patients in this group (labeled NC-not classified) had sustained brain damage from a variety of aetiologies, including tumors, subarachanoid hemorrhage, intracerebral hemorrhage, small vessel disease, and encephalitis.

The data of patients who evidenced severe problems during participation were excluded from further analysis. We used two exclusion criteria. Six BD patients (TBI: 1, RBD: 1, NC: 4) were excluded because they could not provide any answers for more than $12 \%$ of the questions. Seven BD patients (TBI: 3, RBD: 1, NC: 3) and one NBD participant were excluded because they showed response tendencies. For more than $67 \%$ of the questions, these participants gave the same response (yes or no). Demographic characteristics of the resulting groups are presented in Table 1.

Nonparametric Kruskal-Wallis tests indicated that the four patient groups were comparable with respect to time post injury $\left(\chi^{2}(3)=4.4\right.$; n.s. $)$, schooling $\left(\chi^{2}(6)=11.7\right.$; n.s. $)$ and gender $\left(\chi^{2}(3)=2.4\right.$; n.s.). There were significant age differences, though $(\mathrm{F}(3,92)=$ $10.8 ; \mathrm{p}<.001)$. Post hoc analyses revealed that patients in the TBI group were significantly younger than both the RBD and LBD groups $(\mathrm{t}(44)=4.4 ; \mathrm{p}<.0001 ; \mathrm{t}(32.3)=4.8$; $\mathrm{p}<.0001$, respectively).

\section{Neuropsychological Diagnosis}

For an evaluation of the relationship between the patients' neuropsychological profiles and their text comprehension skills, test results from the clinical diagnosis were used. The selection of test scores was similar to that of previous patient studies on text comprehension (Ferstl, Guthke \& von Cramon, 1999; 2002), focussing on language, verbal learning and memory, and executive functions, but also including test scores assessing general intelligence and attention. Not all scores were available for each patient. The clinical diagnosis of cognitive deficits had been carried out independently of the administration of the SCT and it was tailored to the therapeutic needs of the individual patient. For instance, the Token Test was administered only when aphasic language problems had been observed by the therapists, or when the patient received speech therapy. The following scores were used:

To evaluate memory deficits the Wechsler Memory Scale-Revised (WMS-R; Wechsler, 1987) was applied for clinical diagnosis. From the test results, we used the general memory 
quotient (MQ), including both verbal and visual memory abilities. In addition we chose the subtest logical memory, testing the recall of two short stories immediately after presentation (Logical Memory 1) and after a delay of 30 minutes (Logical Memory 2). Verbal working memory was assessed using the WMS-R subtest Digit Span (forwards and backwards), and with the subtest Working Memory of the TAP-test (Testbatterie zur Aufmerksamkeitsprüfung [Test of Attentional Processes] Zimmermann \& Fimm, 1992). The latter test consists of a two-back task and requires the continuous comparison between the currently presented number and the next to last one. Relevant were the number of omissions.

Verbal learning ability was assessed with a list learning test similar to the California Verbal Learning Test (CVLT; Delis, Kramer, Kaplan \& Obler, 1987). The patients are required to memorize a list of 16 auditorily presented nouns from four different categories. The list is presented a total of five times, so that in addition to the initial recall ability the course of learning can be evaluated. We selected the total number of words recalled during the five trials.

As an assessment of executive dysfunctions results from the Behavioural Assessment of Dysexecutive Syndrome (BADS; Wilson, Alderman, Burgess, Emslie \& Evans, 1996) were available. Subjects are presented six unstructured task that are designed to reflect daily life situations. The scores for each subtest were summed to a total profile score. Higher scores reflect better executive functions.

We also selected the subtest 3 of the LPS (Leistungsprïfsystem; Horn, 1983). This test required conductive reasoning, an aspect of executive functions, and is used to screen for deficits in general, nonverbal intelligence. The subtest consists of a series of systematically related symbol sequences. The task is to identify in each sequence the one element violating the rule for relating the other symbols. In addition we assessed the premorbid verbal IQ using the German intelligence test Mehrfachwahl-Wortschatz-Intelligenztest ([Multiple choice vocabulary intelligence test], Lehrl, Merz, Burkhard \& Fischer, 1991). The participants are required to select a word from four other pseudo-words (e.g. Amarica Acarina - Amacira - America - Amaci).

As a screening for attentional deficits the results of two subtests of the TAP-Test were used. The information processing speed was assessed with the subtest Alertness. This subtest measures simple reaction times to briefly presented stimuli. The subtest Divided Attention requires the simultaneous consideration of auditory and visual stimuli. As an index for impaired divided attention the number of omissions was taken.

Aphasic language deficits were evaluated with the subtest Token Test (cf. de Renzi \& Faglioni, 1978) from the Aachen Aphasia Test (AAT; Huber, Poeck \& Willmes, 1984).

A summary of the test scores for the four patient groups is presented in Table 2. Oneway ANOVAs were used to test for each score the differences between the groups. The only significant results were the Logical Memory scores and the digit span scores, where RBD patients showed superior performance. In particular, the LBD patients had lower digit spans, consistent with impairments of phonological memory in aphasia (e.g., Rönnberg et al., 1996), and TBI patients had difficulties remembering story information (e.g., Haut, Petros \& Frank, 1990).

\section{Material}

Two stories were written, one about a hiking trip, and the other about going shopping. Each story was about 650 words long. Similar to Brookshire and Nicholas (1993) the text comprehension was tested with yes/no questions. The questions crossed two factors: the salience and explicitness of the queried information. They either asked about main ideas 


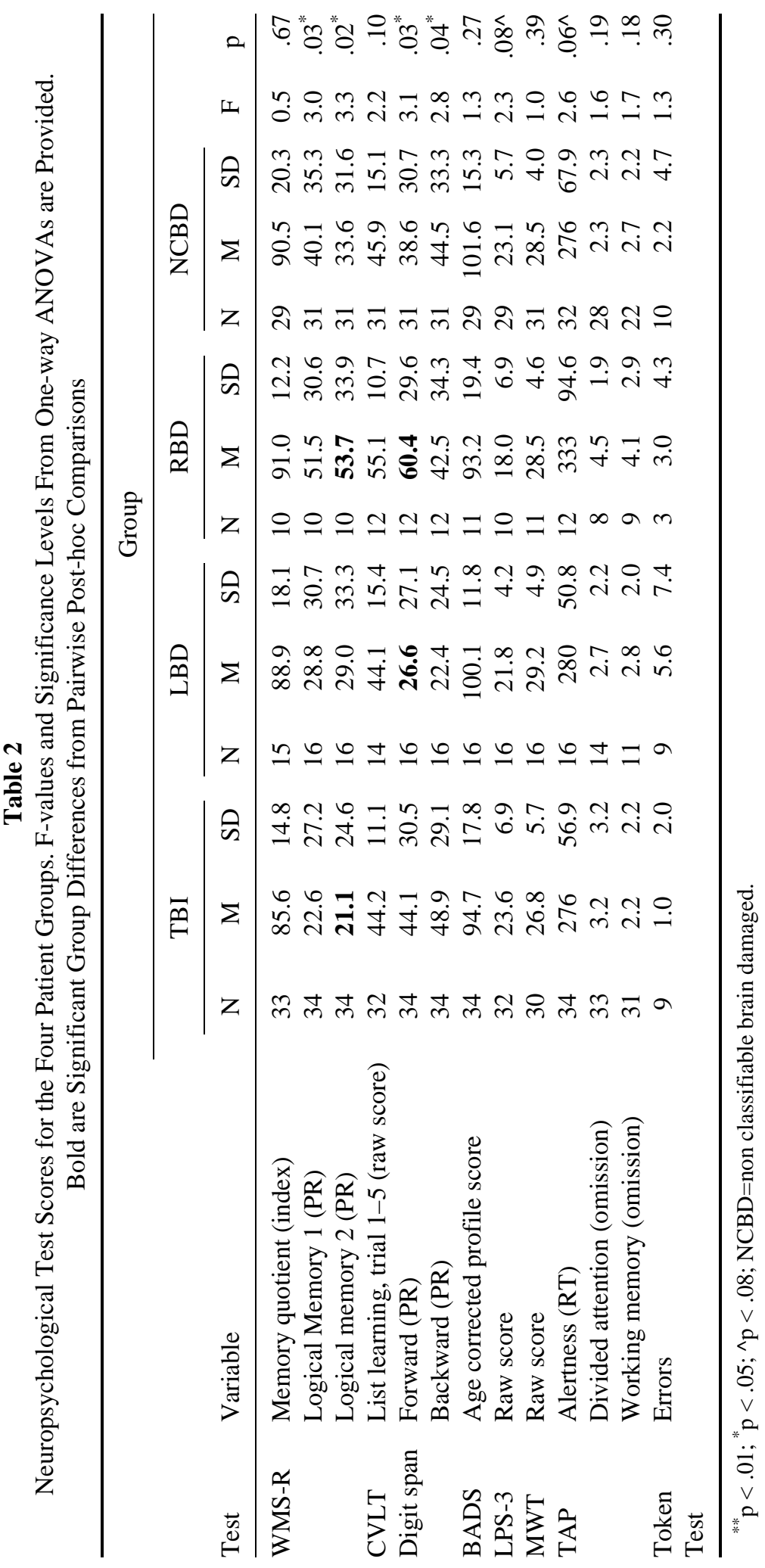


... It was half past seven. The sun was about to rise above the city of Leipzig when in the Millers' bedroom the alarm clock started to ring. As every year, they wanted to go on a hike in the woods to relax from the exhausting work week and their stuffy offices. The previous evening they had picked a hiking trail. That's why Herbert got up immediately and brushed his teeth. When he was done, he prepared breakfast, while Margot got ready. A wonderful coffee aroma awaited her when she came out of the bathroom. Herbert had set the table, toasted some bread and boiled some eggs. They had a leisurely breakfast and then they prepared sandwiches to take along on the hike. In addition, they packed some fruit, a thermos full of tea and a couple of eggs. Herbert put on his brown knickerbockers, his green socks and a thick sweater, while Margot wore her favorite jeans and the blue outdoor jacket. ...

... The path became steeper and steeper. Wooden stairs and stone steps alternated. The incline taxed their indurance, and they were panting. Margot had to unbotton her jacket, since she started sweating. A full one and a half hours they had been on their way but they were not even close to their destination. Finally, they took a short break, because their legs hurt so much. After they had somewhat recovered, they hiked the last stretch to the summit. Completely exhausted they reached the platform. The fantastic view made up for the effort of the long climb. They looked down upon a colorful landscape of trees with green, yellow and red leaves. ...

\begin{tabular}{lll} 
stated main idea & Did the couple go on a business trip? & no \\
& Had they planned the trip? & yes \\
implied main idea & Did they depart after lunch? & no \\
& Was the trip strenuous? & yes \\
\multirow{3}{*}{ stated detail } & Did they take tea along? & yes \\
& Did Herbert wear brown socks? & no \\
implied detail & Did the man go to the bakery? & no \\
& Did the trip take place in autumn? & yes
\end{tabular}

Figure 1. Story excerpt, translated from the original German, and examples for the four question types.

of the text or about details, and they asked about explicitly stated information or about information that needed to be inferred by the reader. Sixteen questions were selected for each story, with four questions in each of the four cells of the Salience (main idea vs. detail) $\times$ Explicitness (explicit vs. implicit) design. For two of the questions in each cell the correct response was YES, for the other two it was NO. Figure 1 displays a translated excerpt of one of the stories and two examples for each question of the Salience $\times$ Explicitness design. The 16 questions for each story were pseudo-randomly ordered in one fixed list, so that the yes and no responses were equally distributed, and the sequential order roughly followed the order of mention in the text.

\section{Procedure}

Each participant was tested individually with both the hiking story and shopping story. The presentation order was randomly assigned. For healthy NBD participants the experiment was part of a larger investigation including a number of other experiments, and it was carried out in one session. The BD patients were tested in one or, if necessary, in two 
sessions by the patient's neuropsychologist or language therapist. The duration of the experiment was approximately 45 minutes.

Before presentation, the subjects were informed that they would hear a story and they were instructed to carefully listen to it. Afterwards, they would be asked to answer questions about its content. The story was then read aloud in an adequate rate and with clear articulation. Immediately after the story presentation, the questions were read to the subjects. The participants responded to each question with a yes/no judgment, which the examiner noted on the questionnaire. The presentation of the second story and its associated questions subsequently proceeded in the same way.

\section{Design}

The dependent variable was the accuracy of the responses. For each subject and each condition, the proportion of errors across the two stories was calculated. The analyses used a mixed factorial design, including the following factors: The within-subject factors were Salience (main ideas vs. details) and Explicitness (stated vs. implied). In addition, we used one between-subjects factor Group. In the first analysis, comparing the whole patient group to the comparison group, the factor Group had two levels (NBD vs. BD). In the second analysis, the factor Group coded the type of brain damage on three levels (LBD, RBD and TBI).

\section{Results}

All performance measures of the NBD and BD groups, additionally split into lesion subgroups of patients (TBI, LBD, RBD) are shown in Table 3.

\section{Comparison Group vs. Brain Damaged Patients}

For a first analysis the performance of all brain damaged participants was compared with that of the non-brain-damaged participants. The error rates are shown in Figure 2 for both groups as a function of question type.

The analysis of variance yielded a significant main effect of Salience $(\mathrm{F}(1,143)=$ 250.4; $\mathrm{p}$ <.001). More questions about main ideas were answered correctly than questions about details (7\% vs. $24 \%$ errors). A corresponding effect was observed for the factor Explicitness $(\mathrm{F}(1,143)=17.5 ; \mathrm{p}<.001)$. Subjects responded to questions about stated information more accurately than to questions about implied information (14\% vs. $18 \%$ errors). The interaction between Salience and Explicitness was also reliable $(\mathrm{F}(1,143)=$ 38.6; $\mathrm{p}<.001)$. The difference between stated and implied questions was only observed for main ideas ( $1 \%$ vs. $12 \%$ errors). In contrast, implied detail information ( $23 \%$ errors) was responded to slightly better than stated detail information ( $26 \%$ errors).

The main effect of Group confirmed that the BD participants made significantly more errors than NBD participants $(17 \%$ vs. $14 \% ;(\mathrm{F}(1,143)=5.9 ; \mathrm{p}<.05)$. Furthermore, the interaction between Group and Explicitness $(\mathrm{F}(1,143)=7.2 ; \mathrm{p}<.01)$, indicated that the performance difference was mostly due to the implicit questions. Post hoc analyses showed that NBD subjects and BD subjects answered questions testing explicitly stated information similarly well $(\mathrm{t}(143)<1$; n.s.). In contrast, BD participants made more errors on questions testing implied information than NBD participants $(\mathrm{t}(130.7)=3.13 ; \mathrm{p}<.01)$. As expected, the interaction between salience and explicitness had a slightly different form than in the DCT studies. In our experiment, the comparison participants had less difficulty with the implied details than with the explicit details. A further pairwise 
Table 3

Error Rates (in Percent) for all Groups as a Function of Salience and Explicitness

\begin{tabular}{|c|c|c|c|c|c|c|c|c|c|}
\hline & \multicolumn{3}{|c|}{ Main ideas } & \multicolumn{3}{|c|}{ Details } & \multicolumn{3}{|c|}{ All } \\
\hline & Stated & Implied & Total & Stated & Implied & Total & Stated & Implied & Total \\
\hline \multicolumn{10}{|c|}{$\begin{array}{l}\text { NBD-subjects } \\
\quad(\mathrm{N}=49)\end{array}$} \\
\hline Mean & 1 & 10 & 6 & 25 & 19 & 22 & 13 & 15 & 14 \\
\hline SD & 4 & 9 & 5 & 16 & 13 & 11 & 8 & 8 & 7 \\
\hline Cut off & 5 & 19 & 11 & 41 & 32 & 33 & 21 & 23 & 21 \\
\hline \multicolumn{10}{|c|}{$\begin{array}{l}\text { BD-subjects } \\
\quad(\mathrm{N}=96)\end{array}$} \\
\hline Mean & 2 & 14 & 8 & 26 & 27 & 27 & 14 & 20 & 17 \\
\hline SD & 4 & 13 & 7 & 16 & 18 & 14 & 8 & 12 & 9 \\
\hline \multicolumn{10}{|c|}{ TBI $(\mathrm{N}=34)$} \\
\hline Mean & 3 & 11 & 7 & 26 & 29 & 27 & 14 & 20 & 17 \\
\hline SD & 5 & 10 & 6 & 14 & 19 & 15 & 8 & 13 & 9 \\
\hline \multicolumn{10}{|c|}{$\operatorname{LBD}(\mathrm{N}=18)$} \\
\hline Mean & 1 & 13 & 7 & 31 & 18 & 25 & 16 & 16 & 16 \\
\hline $\mathrm{SD}$ & 4 & 12 & 7 & 22 & 14 & 15 & 11 & 11 & 9 \\
\hline \multicolumn{10}{|c|}{$\operatorname{RBD}(\mathrm{N}=12)$} \\
\hline Mean & 0 & 14 & 7 & 16 & 26 & 21 & 8 & 20 & 14 \\
\hline SD & 0 & 16 & 8 & 11 & 16 & 11 & 5 & 12 & 8 \\
\hline
\end{tabular}

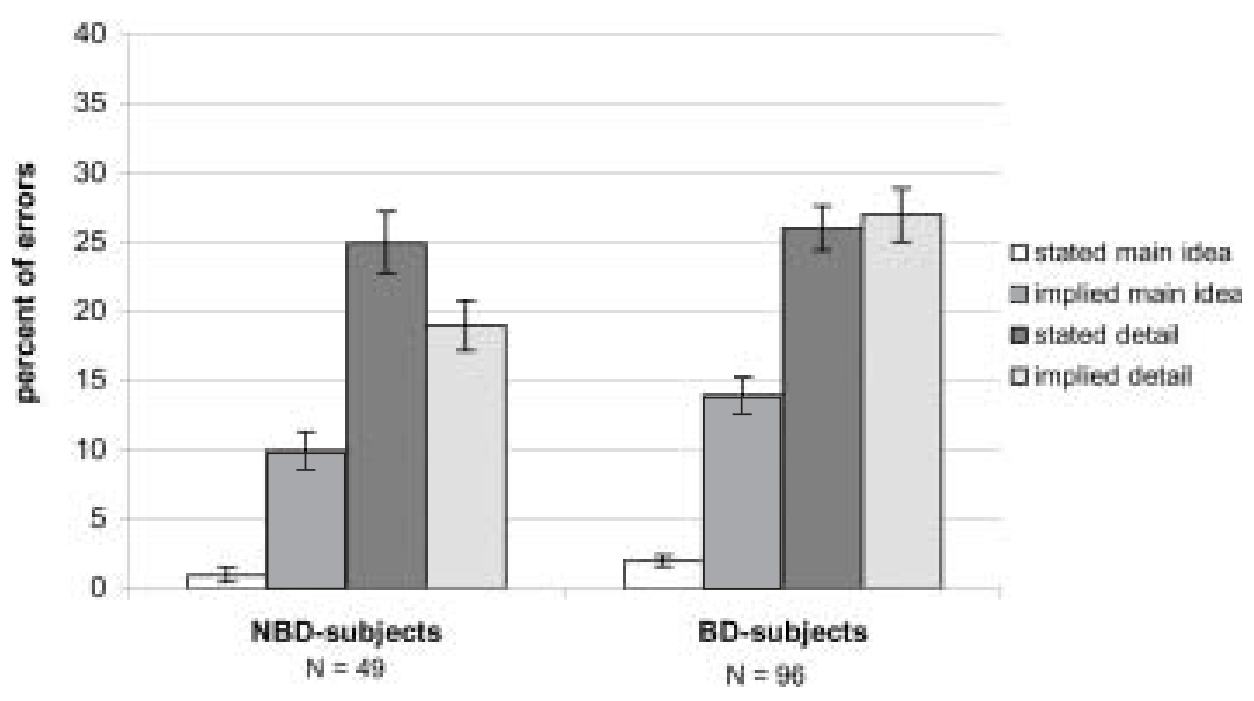

Figure 2. Percentage of errors as a function of question type, for comparison participants (NBD) and brain damaged patients (BD). Shown are the means and the standard errors.

comparison for the comparison group only confirmed that this difference was significant $(t(48)=2.42 ; \mathrm{p}<.05)$. These results show that the SCT yielded quantitative as well as qualitative differences in performance for the patient group compared to the comparison group. 


\section{Aetiology}

The second analysis evaluated the effects of aetiology. Using the classification of Nicholas and Brookshire (1995) we selected those 64 patients who could be assigned to one of the three subgroups TBI, LBD and RBD (see Method section and Table 1). A mixed ANOVA with the within-subjects factors Salience and Explicitness and the between-subjects factor group was conducted to test whether the aetiology yielded systematic differences in question answering performance.

As in the analysis including all participants, both main effects and the interaction were highly significant (Salience: $\mathrm{F}(1,61)=83.6$; $\mathrm{p}<.001$; Explicitness: $\mathrm{F}(1,61)=13.2$; $\mathrm{p}<.001$; Salience $x$ Explicitness: $\mathrm{F}(1,61)=16.1 ; \mathrm{p}<.001)$.

The overall performance level was comparable for the three patient groups. However, the factor Aetiology influenced the response patterns, as evidenced in the following reliable interactions: Aetiology x Explicitness $(\mathrm{F}(2,60)=4.5 ; \mathrm{p}<.02)$ and Aetiology x Explicitness $\mathrm{x}$ Salience $(F(2,60)=5.7 ; p<.01)$. Thus, the different patient groups did not differ quantitatively in their question answering performance, but there was a systematic difference between the four question types. For both TBI and RBD patients, there was the expected increase in difficulty for the implicit information, but this effect was not found for LBD patients. Furthermore, this group difference was mostly due to the detail questions. Figure 3 illustrates that LBD patients made more errors on questions about explicit details than about implicit details, for TBI patients, the error rates were comparable, and for the RBD patients, the pattern was even reversed. Pairwise comparisons showed that LBD patients performed better on implied details than TBI patients $(\mathrm{t}(50)=2.0 ; \mathrm{p}<.05)$, and that RBD patients performed better on stated details than both TBI and LBD patients $(\mathrm{t}(44)=2.3 ; \mathrm{p}<.05 ; \mathrm{t}(26.3)=2.6 ; \mathrm{p}<.05)$.

\section{Diagnostic utility}

The qualitative differences in the group statistics show that the SCT captures systematic differences in text comprehension performance. For clinical applications it is important,

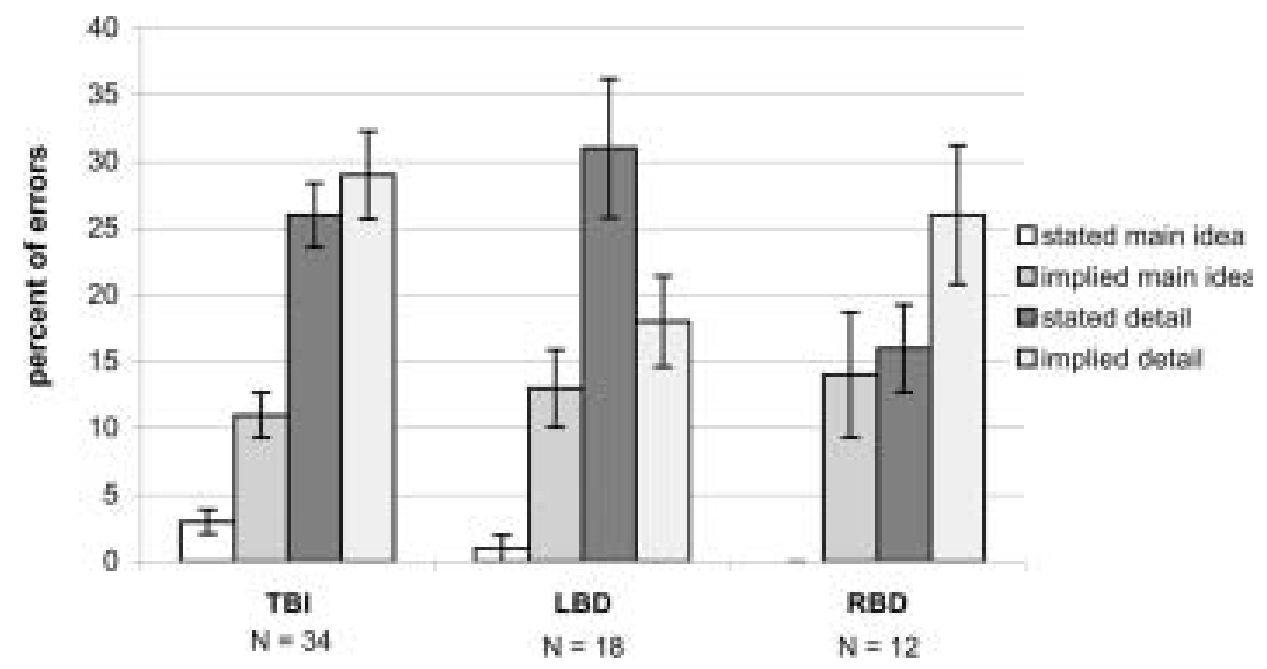

Figure 3. Percentage of errors as a function of question type and patient group (TBI = traumatic brain injury, $\mathrm{LBD}=$ left-hemispheric insult, $\mathrm{RBD}=$ right-hemispheric insult). Shown are the means and the standard errors. 
however, to be able to diagnose individuals' comprehension deficits. In particular, the SCT should provide the means to classify a given patient's performance as impaired or in the normal range. Furthermore, in the case of hints at a deficit, the therapist must be interested in a qualitative description of the subprocesses particularly affected. In the following section an evaluation of the SCT with respect to the utility for clinical diagnosis is attempted.

As a basis for the assessment of text comprehension performance, the data from the NBD group were used to determine threshold values for impaired comprehension. For each question type separately, a cutoff of one standard deviation above the group mean was defined. In addition, we defined combined cutoffs reflecting the main effects of the test (i.e., main ideas, details, stated, and implicit). All cutoff values are included in Table 3.

For the patients in the BD group and each of the resulting nine variables, we then coded whether they were impaired, that is, whether their error rate exceeded the cutoff value. The percentages of patients falling out of the normal range were determined for each of the patient subgroups. For the total performance only, we also considered those patients as impaired who had been excluded from the analysis (see Method section) because they had not been able to perform the task. Finally, $\chi^{2}$ tests for each of the variables were used to determine whether the patient group significantly differed from the comparison group. The results are shown in Table 4.

The comparison between NBD participants and BD patients confirmed the results from the group analysis: twice as many patients were above the cutoff in total performance. In the TBI group more patients were impaired than in the two groups with vascular aetiologies (LBD and RBD). Interestingly, there were qualitative differences between the question types. Overall, the deviations from the NBD group performance was visible mainly on the main ideas and the implied information, but not on the stated and detail information. More specific were the distributions for the three lesion groups, and they also converged with the previous analyses. We observed dissociable deficits for patients with TBI, LBD and RBD. A large proportion of TBI patients had particular problems in answering of implied questions (main ideas and details taken together). More than $40 \%$ of these patients were over the cutoff. In contrast, LBD patients revealed difficulties with answering questions about stated information, and in particular, questions testing stated details. Finally, for the RBD patients the questions about implied main ideas uncovered the clearest deviation from the NBD group's response pattern.

Table 4

Percentage of Participants with Impaired Performance on the Different Question Types

\begin{tabular}{lccccr}
\hline & NBD & BD & TBI & LBD & RBD \\
\hline Total & 16.0 & $30.7^{* *}$ & $34.2^{*}$ & 27.8 & 28.6 \\
Stated main idea & 10.2 & 13.5 & 20.6 & 11.1 & 0.0 \\
Implied main idea & 14.3 & $33.3^{*}$ & 26.5 & $27.8^{*}$ & $41.7^{*}$ \\
Stated detail & 10.2 & 13.5 & 11.8 & $33.3^{*}$ & 0.0 \\
Implied detail & 16.3 & $36.5^{* *}$ & $32.4^{\wedge}$ & 22.2 & 33.3 \\
Main idea & 18.4 & $37.5^{*}$ & $35.3^{\wedge}$ & 27.8 & 41.7 \\
Detail & 14.3 & 24.0 & 20.6 & $33.3^{\wedge}$ & 8.3 \\
Stated & 12.2 & 17.7 & 17.6 & $38.9^{*}$ & 0.0 \\
Implied & 10.2 & $40.2^{* *}$ & $41.2^{* *}$ & 22.2 & $33.3^{\wedge}$ \\
\hline
\end{tabular}

$\hat{\mathrm{p}}<.08 ;{ }^{*} \mathrm{p}<.05 ;{ }^{* *} \mathrm{p}<.01$ one-tailed. 


\section{Correlations Between SCT and the Neuropsychological Test Scores}

To examine the relationship between patients' neuropsychological profiles and their story comprehension abilities, correlations between the test scores and the neuropsychological test results (see Table 2) were calculated. Non-parametric Spearman rank order correlations were used because of the different distributions and scales of the various test scores and to reduce the impact of outliers. All patients for whom the test scores were available contributed to these correlations, independent of lesion lateralization or aetiology. The results are shown in Table 5 .

The total percentage of errors was significantly correlated with verbal long-term memory, verbal learning (WMS-R, CVLT) and executive dysfunction (BADS, LPS-3). An inspection of the correlations with the error rates for the four question types suggests that these overall correlations reflect qualitatively different processes. While stated main ideas, stated details and implied details were particularly difficult for those patients who had low memory scores, the implied main ideas were particularly difficult for those patients with worse performance in the executive function tests (BADS, LPS-3 and also digit span backwards). In addition, the MWT, a measure of premorbid verbal intelligence was correlated with the total performance, reflecting mostly the errors on the detail questions.

The working memory measures were also differently predictive of SCT performance. While the digit span forwards, a measure reflecting mainly storage, tended to be correlated with the errors on stated details, both the 2-back task from the TAP-test and the digit span backwards were correlated with the performance on implicit main ideas. These latter working memory measures tap the executive component of working memory more than

\section{Table 5}

Rank Order Correlations Between Neuropsychological Test Results (Raw Scores) and Experimental Variables.

\begin{tabular}{|c|c|c|c|c|c|c|c|}
\hline \multirow[b]{2}{*}{ Test } & \multirow[b]{2}{*}{ Variable } & \multirow[b]{2}{*}{$\mathrm{n}$} & \multicolumn{5}{|c|}{ Experimental variables } \\
\hline & & & Total & $\begin{array}{c}\text { Stated } \\
\text { main ideas }\end{array}$ & $\begin{array}{c}\text { Implied } \\
\text { main ideas }\end{array}$ & $\begin{array}{l}\text { Stated } \\
\text { details }\end{array}$ & $\begin{array}{l}\text { Implied } \\
\text { details }\end{array}$ \\
\hline \multirow[t]{3}{*}{ WMS-R } & Memory quotient & 87 & $-.36^{* *}$ & $-.20^{\wedge}$ & -.12 & $-.30^{* *}$ & $-.39^{* *}$ \\
\hline & Logical memory 1 & 91 & $-.35^{* *}$ & $-.23^{*}$ & -.07 & $-.36^{* *}$ & $-.33^{* *}$ \\
\hline & Logical memory 2 & 91 & $-.42^{* *}$ & $-.23^{*}$ & -.13 & $-.42^{* *}$ & $-.35^{* *}$ \\
\hline CVLT & List learning, trial $1-5$ & 90 & $-.36^{* *}$ & -.17 & -.07 & $-.39^{* *}$ & $-.27^{*}$ \\
\hline \multirow[t]{2}{*}{ Digit span } & Forward & 94 & -.12 & -.08 & -.15 & $-.20^{\wedge}$ & .06 \\
\hline & Backward & 94 & -.09 & .06 & $-.24^{*}$ & -.14 & .13 \\
\hline BADS & Profile score & 90 & $-.28^{* *}$ & -.10 & $-.34^{* *}$ & -.17 & -.13 \\
\hline LPS-3 & Sum of correct answers & 87 & $-.20^{\wedge}$ & -.16 & $-.26^{*}$ & -.06 & -.07 \\
\hline MWT & Sum of correct answers & 88 & $-.30^{* *}$ & -.16 & -.12 & $-.21^{\wedge}$ & $-.22^{*}$ \\
\hline \multirow[t]{3}{*}{ TAP } & Alertness (RT) & 94 & -.06 & $-.21^{*}$ & .11 & .00 & -.15 \\
\hline & $\begin{array}{l}\text { Divided attention } \\
\text { (omissions) }\end{array}$ & 83 & .04 & -.03 & .05 & -.13 & .10 \\
\hline & $\begin{array}{l}\text { Working memory } \\
\text { (omissions) }\end{array}$ & 73 & .18 & .07 & $.26^{*}$ & .09 & .10 \\
\hline Token & Errors & 31 & .06 & -.06 & -.11 & .21 & .11 \\
\hline
\end{tabular}

$$
{ }^{*} \mathrm{p}<.05 ;{ }^{* *} \mathrm{p}<.01 ; \hat{p}<.08
$$


the digit span forwards. Thus, these results are also consistent with the finding of the comprehension of implicit main ideas being related to tests on executive functions.

Despite the relatively large sample, some of these correlation coefficients are significant at the .05 level, but only moderate in magnitude. The clear differences between the implicit main idea scores on one hand, and the stated detail scores on the other, remain visible even when adopting a more stringent criterion for the interpretation of the mulitple correlations. If only those correlations are interpreted that account for at least $10 \%$ of the variance (i.e., $|r|>.316$ ), performance on implicit main ideas still proves to be related to an executive function test (BADS). In contrast, performance on the stated details was clearly correlated with the verbal learning scores (Logical Memory 1 and 2, CVLT1-5)

The lack of a significant correlation with the Token Test results is probably due to the relatively small sample contributing to these correlations. However, the direction of the correlation for the stated details is consistent with the finding of the LBD patients having particular problems with this question type.

\section{Discussion}

In this study the clinical utility of a new German story comprehension test (SCT) was evaluated. Similar to the Discourse Comprehension Test (DCT; Brookshire \& Nicholas, 1993), the instrument consists of the auditory presentation of stories, followed by yes/no questions that systematically target inference processes and the building of a macrostructure. In contrast to the DCT, the stories were longer and thus more demanding with respect to both comprehension processes as well as memory requirements. Nevertheless, the overall performance of a healthy comparison group was very good and it did not vary with the demographic factors age, education, or gender. Furthermore, the comparison groups' results confirmed that both the explicitness of the queried information as well as its salience had a clear impact on question difficulty. As expected, questions about main ideas were easier than details, and questions about explicit information were easier than those about implicit information. In contrast to previous DCT results, however, the interaction between these two factors was partly caused by the somewhat unexpected effect of the explicit details being slightly more difficult than the implicit details. This result might be due to the length of the stories, prohibiting the complete encoding of explicitly mentioned detail information.

For a large, unselected group of brain damaged patients, consecutively admitted to a day clinic, the overall performance level was lower than that of the NBD comparison group. Most importantly, the performance differed not only quantitatively, but it varied systematically with the question condition. Correlations with neuropsychological test scores suggested that the responses on implicit main ideas were closely related to tests of executive functions, whereas performance on the other three question types was predicted by measures of verbal long-term memory and verbal learning.

Similar to the findings of Murray and Stout (1999), there were no obvious relationships between auditory language comprehension as measured by the Token Test (de Renzi \& Faglioni, 1978) and SCT performance. This finding confirms the claim that comprehension of discourse is not directly related to comprehension on the word and sentence level (e.g. Caplan \& Evans, 1990).

Similarly, there were no correlations between verbal working memory and overall SCT performance. This finding is in line with numerous studies showing that memory for complex verbal information is not directly related to span measures (Danemann \& Carpenter, 1980), but that verbal skills play a considerable role. 
The patterns of correlations confirm that the different question types tap dissociable cognitive processes. Whereas the encoding of explicit information depends on working and long-term memory, as well as verbal skills, inferencing processes recruit executive functions needed for integrating different information sources with each other and with the background knowledge.

These systematic differences between the question types were also reflected in the group analysis. Across the entire group of BD participants, only the implicit information, but not the explicit information was difficult. When further subdividing the patient group according to lesion lateralization and aetiology, similar to the groups studied by Nicholas and Brookshire (1995), the sensitivity of the SCT was further confirmed. Quantitatively, the performance was comparable for the TBI, RBD and LBD patients. Qualitatively, however, the three groups differed considerably, as evidenced by the distinct patterns of errors across the four question types.

The results for the main ideas were similar to that of the comparison group, but with the implicit main ideas being more difficult for the RBD group. The most apparent group effects were seen in the responses to detail questions. For the TBI group, both questions about stated and implied details were answered correctly equally often. When comparing this result with the comparison group's data, it can be seen that the advantage for the implied details disappeared, indicating that TBI patients had more difficulties with inferencing. This finding was confirmed by using a cutoff value for identifying impaired patients. More than $40 \%$ of the TBI patients had difficulties with the implicit questions.

For the LBD group, implicit questions were responded to better than stated information. This somewhat counterintuitive result can be explained by compensatory strategies. LBD patients are more likely to have deficits, even slight ones, concerning language processes on the word and sentence level, and consequently the encoding of verbal information. Thus, they rely more on the use of contextual cues, on general world knowledge and on situation model representations (cf. Ferstl, 2001; Ferstl \& Kintsch, 1999; van Dijk $\&$ Kintsch, 1983) than on the surface level. The explicit detail questions did not allow for any of these gist-based comprehension strategies. In contrast, the implicit detail questions combined several content units from the text and were thus more likely to be part of the situation model.

Finally, for the RBD group there was a strong and reliable effect in the opposite direction. Inferences were difficult to draw, as indicated by a large increase of errors in the implicit condition compared to the explicit condition. This result is consistent with previous studies showing inference deficits in RBD patients (Beeman, 1993; Brownell \& Martino, 1998). Moreover, the finding could not be caused by verbal memory processes, because the RBD patients had superior test scores in this area.

In summary, the SCT showed systematic and predicted differences between the two patient groups most likely to be affected by non-aphasic language deficits and the patient groups more prone to aphasic language deficits. These results are consistent with the literature on text comprehension processes after brain damage. However, from a theoretical point of view, the criteria for defining the three groups seem rather coarse. In particular, for the TBI patients, we did not take into account lesion localization or lateralization. However, the main purpose of the study was to provide a clinical assessment tool, and differential information regarding the expected results. Thus, a patient classification based on the general medical diagnosis seemed more useful than a fine-grained lesion categorization that might not be available to the therapist in a clinical setting.

The SCT is an ecologically valid means for diagnosing individual patients' comprehension abilities, independent of their aetiologies or lesion locations. A more specific 
attribution of a resulting deficit requires further evaluation of the concurrent neuropsychological profile.

\section{Clinical Application}

The current study clearly confirms that the SCT is suitable for the application in a clinical setting, and provides a differentiated assessment of story comprehension deficits. The yes/no question format does not require language production, so the test is appropriate for aphasic patients as well as patients with non-aphasic discourse production deficits. In addition, the SCT is easily administered and scored and it has high ecological validity. Furthermore, the reported results suggest a qualitative differentiation of subprocess of text comprehension. Using the cutoff values for the four question types, the SCT provides information about which specific text comprehension subprocess are impaired compared to a comparison population. And for patients with vascular or traumatic aetiology, an additional comparison with the qualitative patterns obtained for the three aetiology groups can shed light on whether the individual patient's performance is typical for his or her group.

Furthermore, a differential diagnosis is useful for patients whose discourse comprehension deficit is likely to be secondary to other cognitive impairments. For instance, when long-term memory encoding is severely disrupted, question answering performance is expected to be poor despite possibly intact comprehension skills. A multi-step procedure is suggested to utilize the SCT for a more thorough evaluation of the influence of memory on question answering performance. During our clinical diagnosis, the test as described here is augmented by two additional steps. After the initial presentation and question answering, the patients receive a written version of the story, and they are allowed to check their previous answers based on a rereading of the stories. In the third step, the therapist discusses all questions, their initial and their corrected responses with the patient. Patients whose main difficulties are in the domains of long-term memory or attention greatly benefit from the written text, whereas patients whose deficit concerns inferencing and information integration will not be able to improve on answers to implicit questions.

Despite high correlations between verbal learning and memory scores and the SCT performance, the test provides information going beyond the usual neuropsychological assessment. Its application seems particularly promising for patients with mild neuropsychological deficits. For instance, one participating patient presented with communication problems including inappropriate answers to questions and apparent disinterest in many conversation topics. His verbal WMS-scores were in the normal range, as were the results of list learning and executive function tests. In contrast, the error pattern in the SCT mirrored that of the RBD group, in that the patient made $25 \%$ errors on questions to implied main ideas, a value clearly above the cutoff. Thus, the observation of the patient's inappropriate or missing responses in conversation might be due to his failure to evaluate the implicit implications of statements made by the conversation partner. This interpretation is further strengthened by the fact that the patient benefitted greatly from feedback and explicit hints during communicative situations.

Despite its specificity, the SCT evaluation can only be one part of a more comprehensive assessment of text comprehension ability. For instance, when the SCT yields evidence for a deficit, an evaluation of discourse production and of other subprocesses of discourse comprehension should follow. In particular, the comprehension of non-literal language (e.g., jokes, metaphors, indirect requests) and the appropriate use of conversational rules 
need to be tested whenever there is evidence for a non-aphasic deficit (cf. Brownell, Michel, Powelson, \& Gardner, 1983; Stemmer, Giroux, \& Joanette, 1994).

\section{Summary}

In this study we presented a story comprehension test developed particularly for a qualitative diagnosis of text comprehension deficits. The test was shown to provide information about qualitatively different subprocesses of comprehension, and to uncover theoretically motivated differences in comprehension skill between patient groups. Moreover, the definition of cutoff values enables us to use the SCT as a diagnostic tool for the evaluation of individual patients' text comprehension deficits.

\section{References}

Beeman, M. (1993). Semantic processing in the right hemisphere may contribute to drawing inferences from discourse. Brain and Language, 44, 80-120.

Brooks, N., McKinlay, W., Symington, C., Beattie, A. \& Campsie, L. (1987). Return to work within the first seven years of severe head injury. Brain Injury, 1, 5-19.

Brookshire, R. H., \& Nicholas, L. E. (1984). Comprehension of directly and indirectly stated main ideas and details in discourse by brain-damaged an non-brain-damaged listeners. Brain and Language, 21, 21-36.

Brookshire, R. H., \& Nicholas, L. E. (1993). The Discourse Comprehension Test. Tucson, AZ: Communication Skill Builders, A Division of the Psychological Corporation.

Brownell, H. H. \& Martino, G. (1998). Deficits in inference and social cognition: The effects of right hemisphere brain damage on discourse. In M. Beeman and C. Chiarello (eds.), Right hemisphere language comprehension: Perspectives from cognitive neuroscience (pp. 309-328). Mahwah, NJ: Lawrence Erlbaum.

Brownell, H. H., Michel, D., Powelson, J. A., \& Gardner, H. (1983). Surprise but not coherence: Sensitivity to verbal humor in right-hemisphere patients. Brain and Language, 18, 20-27.

Caplan, D. (1992). Language: Structure, processing, and disorders. Cambridge, MA: MIT Press.

Caplan, D., \& Evans, K. L. (1990). The effects of syntactic structure on discourse comprehension in patients with parsing impairments. Brain and Language, 39, 206-234.

Chapman, S. B., Levin, H. S., \& Culhane, K. A. (1995). Language impairment in closed head injury. In H. S. Kirshner (ed.), Handbook of neurological speech and language disorders (pp. 387-414). New York: Marcel Dekker.

Danemann, M., \& Carpenter, P. A. (1980). Individual differences in working memory and reading. Journal of Verbal Learning and Verbal Behavior, 19, 450-466.

Delis, D. C., Kramer, J. H., Kaplan, E., \& Obler, B. A. (1987). The California verbal learning test: Adult version. San Antonio, TX: The Psychological Corporation.

de Renzi, E., \& Faglioni, P. (1978). Normative data and screening power of a shortened version of the Token Test. Cortex, 14, 41-49.

Ferstl, E. C. (2001). Learning from Text. In N. J. Smelser \& P. B. Baltes (eds.), International encyclopedia of the social \& behavioral sciences, Volume 3.13: Cognitive Psychology and Cognitive Science (ed. W. Kintsch). Amsterdam: Elsevier.

Ferstl, E. C., Guthke, T., \& von Cramon, D. Y. (1999). Change of perspective in discourse comprehension: Encoding and retrieval processes after brain injury. Brain and Language, 70, 385-420.

Ferstl, E. C., Guthke, T. \& von Cramon, D. Y. (2002). Text comprehension after brain injury: Left prefrontal lesions affect inference processes. Neuropsychology, 16, 292-308.

Ferstl, E. C., \& Kintsch, W. (1999). Learning from text: Structural knowledge assessment in the study of discourse comprehension. In H. Oostendorp \&. S. Goldman (eds.), The construction of mental models during reading, (pp. 247-277). Mahwah, NJ: Lawrence Erlbaum. 
Germani, M. J., \& Pierce, R. S. (1992). Contextual influences in reading comprehension in aphasia. Brain and Language, 42, 308-319.

Graesser, A. C., Singer, M. \& Trabasso, T. (1994). Constructing inferences during narrative text comprehension. Psychological Review, 101, 371-395.

Guthke, T., Hauptmann, A., \& Ferstl, E. C. (2001). Empirische Untersuchung zur Textverarbeitung bei hirngeschädigten Patienten [Empirical studies on text comprehension after brain damage]. Aphasie und verwandte Gebiete, 15, 29-41.

Hartley, L. L., \& Levin, H. S. (1990). Linguistic deficits after closed head injury: A current appraisal. Aphasiology, 4, 353-370.

Haut, M. W., Petros, T. V., \& Frank, R. G. (1990). The recall of prose as a function of importance following closed head injury. Brain Injury, 4, 281-288.

Horn, W. (1983). Leistungsprüfsystem (LPS) [Performance assessment system]. Göttingen: Verlag für Psychologie.

Hough, M. S. (1990). Narrative comprehension in adults with right and left hemisphere braindamage: Theme organization. Brain and Language, 38, 253-277.

Huber, W., Poeck, K., \& Willmes, K. (1984). The Aachen Aphasia Test. In F. C. Rose (ed.), Advances in neurology, Vol. 42: Progress in aphasiology. New York: Raven Press.

Kaczmarek, B. L. J. (1984). Neurolinguistic analysis of verbal utterances in patients with focal lesions of frontal lobes. Brain and Language, 21, 52-58.

Kaczmarek, B. L. J. (1987). Regulatory function of the frontal lobes: A neurolinguistic perspective. In E. Perecman (ed.), The frontal lobes revisited, (pp. 225-240). Hillsdale, NJ: Lawrence Erlbaum.

Kintsch, W. (1998). Comprehension: A paradigm for cognition. Cambridge: Cambridge University Press.

Kintsch, W., \& van Dijk, T. A. (1978) Toward a model of text comprehension and production. Psychological Review, 85, 363-394.

Lehmann, M.T. \& Tompkins, C.A. (2000). Inferencing in adults with right hemisphere brain damage: An analysis of conflicting results. Aphasiology, 14 (5-6),485-499.

Lehrl, S., Merz, J., Burkhard, G., \& Fischer, B. (1991). Mehrfachwahl-Wortschatz-Intelligenztest (MWT-A). [Multiple choice vocabulary intelligence test]. Erlangen, D: Perimed.

Levin, H. S., Amparo, E., Eisenberg, H. M., Williams, D. H., High, W. M. Jr., McArdle, C. B., \& Weiner, R. L. (1987). Magnetic resonance imaging and computerized tomography in relation to the neurobehavioral sequelae of mild and moderate head injuries. Journal of Neurosurgery, 66, 706-713.

McDonald, S. (1993). Viewing the brain sideways? Frontal versus right hemisphere explanations of non-aphasic language disorders. Aphasiology, 7, 535-549.

McDonald, S. \& Wales, R.(1986). An investigation of the ability to process inferences in language following right hemisphere brain damage. Brain and Language, 29, 68-80.

Murray, L. L. \& Stout, J. C. (1999). Discourse comprehension in Huntington's and Parkinson's diseases. American Journal of Speech-Language Pathology, 8, 137-148.

Nicholas, L. E., \& Brookshire, R. H. (1986). Consistency of the effects of rate of speech on braindamaged adults' comprehension of narrative discourse. Journal of Speech and Hearing Research, $29,462-470$.

Nicholas, L. E., \& Brookshire, R. H. (1995). Comprehension of spoken narrative discourse by adults with aphasia, right-hemisphere brain damage, or traumatic brain injury. American Journal of Speech-Language Pathology, 4, 69-81.

Novoa, O. P., \& Ardila, A. (1987). Linguistic abilities in patients with pre-frontal damage. Brain and Language, 30, 206-225.

Pierce, R. S. (1988). Influence of prior and subsequent context on comprehension in aphasia. Aphasiology, 2, 577-582.

Prigatano, G. P., Roueche, J. R., Fordyce, D. J. (1986). Nonaphasic language disturbances after brain injury. In G. P. Prigatano, D. J. Fordyce, H. K. Zeiner, J.R. Roueche, M. Pepping, B. C. Wood (eds.), Neuropsychological rehabilitation after brain injury. Baltimore, MD: John Hopkins University Press. 
Rönnberg, J., Larsson, C., Fogelsjöö, A., Nilsson, L.-G., Lindberg, M., \& Ängquist, K.-A. (1996). Memory dysfunction in mild aphasics. Scandinavian Journal of Psychology, 37, 46-61.

Singer, M. (1994). Discourse inference processes. In M. A. Gernsbacher (ed.), Handbook of psycholinguistics (pp. 479-515). San Diego, Ca: Academic Press.

Stemmer, B., Giroux, F. \& Joanette, Y. ( 1994). Production and evaluation of requests by right hemisphere brain-damaged individuals. Brain and Language, 47, 1-31.

Ulatowska, H. K., \& Chapman, S. B. (1994). Macrostructure in aphasia. In R. L. Bloom, L. K. Obler, S. De Santi, \& J. S. Ehrlich (eds.), Discourse analysis and applications: Studies in adult clinical populations (pp. 29-46). Hillsdale, NJ: Lawrence Erlbaum.

van Dijk, T. A. \& Kintsch, W. (1983) Strategies of discourse comprehension. New York, Academic Press.

Webster, J. S., Godlewski, M. C., Hanley, G. L., \& Sowa, M. V. (1992). A scoring method for logical memory that is sensitive to right-hemispheric dysfunction. Journal of Clinical and Experimental Neuropsychology, 14, 222-238.

Wechsler, D. (1987). Wechsler memory scale-revised. NY: Psychological Corporation.

Wegner, M. L., Brookshire, R. H. \& Nicholas, L. E., (1984). Comprehension of main ideas and details in coherent and noncoherent discourse by aphasic and nonaphasic listeners. Brain and Language, 21, 37-51.

Welland, R. J., Lubinski, R. \& Higginbotham, D. J. (2002). Discourse comprehension test performance of elders with dementia of the Alzheimer type. Journal of Speech, Language and Hearing Research, 45, 1175-1187.

Wilson, B., Alderman, N., Burgess, P. W., Emslie, H., \& Evans, J. J. (1996). Behavioural assessment of the dysexecutive syndrome. Bury St. Edmunds, GB: Thames Valley Test Company.

Zimmermann, P., \& Fimm, B. (1992). Testbatterie zur Aufmerksamkeitsprïfung (TAP) [Test battery for the assessment of attention]. Würselen, Germany: Psychologische Testsysteme. 